\title{
Temperature-Sensitive Poly(N-isopropylacrylamide)/Konjac Glucomannan/Graphene Oxide Composite Membranes with Improved Mechanical Property, Swelling Capability, and Degradability
}

\author{
Guohong Zou, ${ }^{1}$ Juan Shen $\left(\mathbb{D},{ }^{1,2}\right.$ Peizhen Duan, ${ }^{1}$ Xu Xia, ${ }^{1}$ Rigui Chen, ${ }^{1}$ and Bo Jin ${ }^{2}{ }^{2}$ \\ ${ }^{1}$ School of Materials Science and Engineering, Southwest University of Science and Technology, Mianyang 621010, China \\ ${ }^{2}$ State Key Laboratory Cultivation Base for Nonmetal Composites and Functional Materials, \\ Southwest University of Science and Technology, Mianyang 621010, China \\ Correspondence should be addressed to Juan Shen; sj-shenjuan@163.com and Bo Jin; jinbo0428@163.com
}

Received 7 November 2017; Revised 31 January 2018; Accepted 8 February 2018; Published 17 April 2018

Academic Editor: Hossein Sojoudi

Copyright (C) 2018 Guohong Zou et al. This is an open access article distributed under the Creative Commons Attribution License, which permits unrestricted use, distribution, and reproduction in any medium, provided the original work is properly cited.

\begin{abstract}
Temperature-sensitive poly(N-isopropylacrylamide)/konjac glucomannan/graphene oxide (PNIPAM/KGM/GO) composite membranes were prepared by solution blending using calcium ions as a cross-linker. The composite membranes were characterized by Fourier-transform infrared spectroscopy (FT-IR), field-emission scanning electron microscopy (FESEM), X-ray diffraction (XRD), Raman spectroscopy (Raman), and differential scanning calorimetry (DSC). The swelling, mechanical property, phase transformation behaviors, and enzymatic degradation activities were also determined. Results revealed that the phase transition temperatures of all the composite membranes were approximately $35^{\circ} \mathrm{C}$. The PNIPAM/KGM/GO composite membranes showed enhanced mechanical property. The swelling behavior and enzymatic degradation of the PNIPAM/KGM/GO composite membranes improved compared with those of conventional PNIPAM hydrogel and PNIPAM/KGM composite membranes. Thus, the PNIPAM/KGM/GO composite membranes have potential applications in the biomedical field as skin dressings.
\end{abstract}

\section{Introduction}

Large skin defect caused by burns or injury is a confoundedly dangerous situation [1]. The unexplained emergence of wounds without effective treatment will lead to tissue necrosis or even more serious consequences [2]. A large number of medical gauze and skin dressings have been developed to prevent wound dryness, infection, and loss of moisture. However, traditional skin dressings are difficult to separate, which would cause secondary damage and high consumption [3]. Therefore, it is of great significance to fabricate a skin dressing that can be automatically and easily stripped.

Currently, stimulus-responsive polymers have been widely investigated because they can respond to changes in the external environments, such as temperature, $\mathrm{pH}$, and light field [4-6]. Among them, poly(N-isopropylacrylamide) (PNIPAM) is one of the most widely studied temperatureresponsive polymers, which possesses a lower critical solution temperature (LCST, approximately $32^{\circ} \mathrm{C}$ ) [7-11]. At temperatures below the LCST, PNIPAM exhibits a hydrophilic and swollen configuration; however, at temperatures above the LCST, PNIPAM becomes hydrophobic and shrunken [12]. PNIPAM is the material commonly used for the preparation of thermoresponsive wound dressing because of its unique thermoresponsive phase transition effect [13-15]. In addition, traditional intelligent hydrogels are limited because of poor mechanical strength, biological properties, and swelling/deswelling performances, which significantly restrict their practical application [16-18]. To deal with this problem and obtain materials with enhanced properties, the present study combines PNIPAM with konjac 

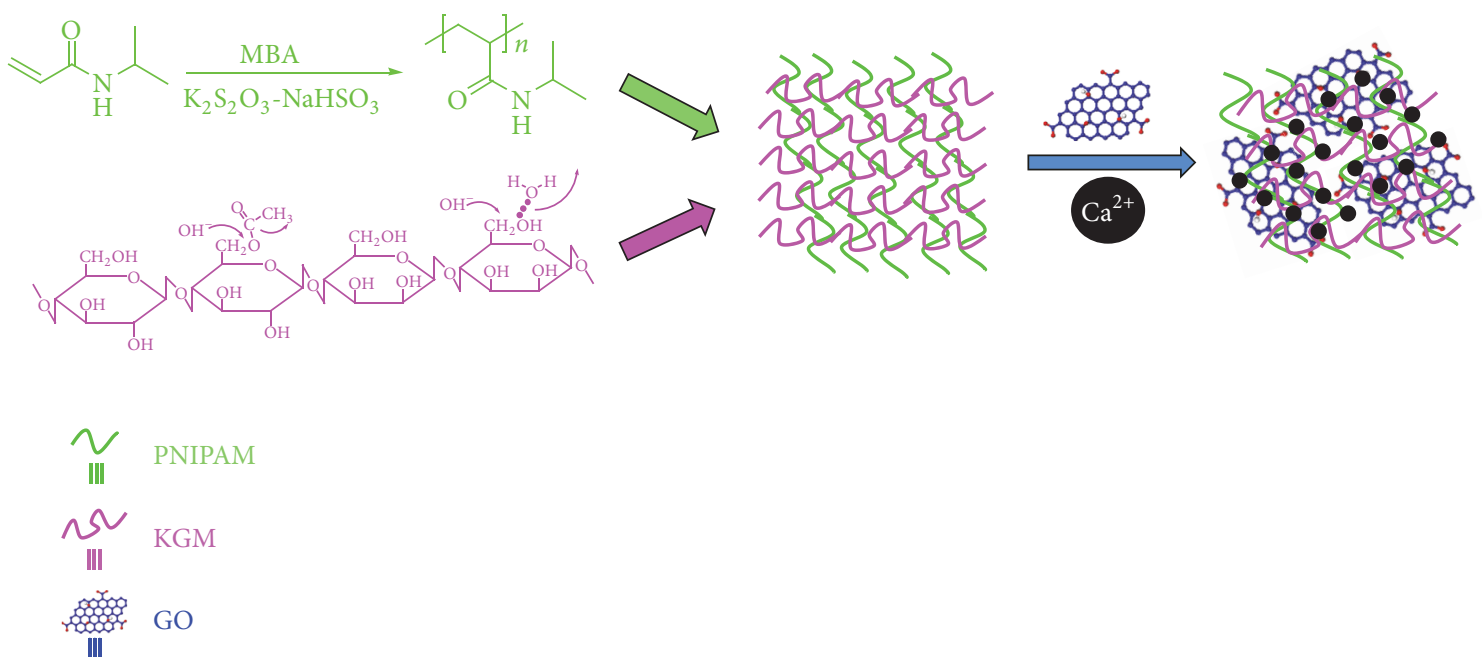

SCHEME 1: Possible mechanism of PNIPAM/KGM/GO composite membranes.

glucomannan (KGM) and graphene oxide (GO) to improve their biological properties and mechanical properties.

Natural biopolymers have attracted tremendous attention because of their excellent properties, such as nontoxicity, biocompatibility, renewability, and biodegradability $[19,20]$. $\mathrm{KGM}$ is a high-molecular-weight polysaccharide and it is composed of $\mathrm{d}$-mannose and $\mathrm{d}$-glucose units linked by $\beta$ $(1,4)$ bonds [21-23]. At present, KGM is increasingly investigated because of its positive properties, such as renewability, biodegradability, and low cost, and it is mainly used in biochemical, medical, and food fields [24].

$\mathrm{GO}$, an oxygen-rich carbonaceous layered material, is a derivative of graphite that is produced by the strong oxidation of graphite $[25,26]$. GO has a large number of oxygencontaining groups, such as carboxyl, epoxy, carbonyl, and hydroxyl, which contribute to its swelling, intercalating, and ion exchange properties [27-30]. Recent researches have been focused on the introduction of a small amount of GO to effectively improve the properties of polymer materials, such as mechanical properties, water absorbing capacity, biocompatibility, and bioactivity, because of the moleculelevel dispersion of GO sheets in a polymer matrix and the strong interfacial interaction between these two components. Park et al. prepared PLGA/GO nanocomposite films, and PLGA/GO (5 wt\%) nanocomposite film showed enhanced tensile strength, Young's modulus, and storage modulus compared with pure PLGA polymer [31]. Zhu et al. introduced an easy, safe, and simple assembly method to fabricate KGM/GO composite films; the final obtained KGM/GO (7.5\%) composite film exhibits significantly enhanced mechanical properties and possesses excellent biocompatibility and bioactivity [32]. Tai et al. reported an "intelligent" graphene oxide/polyacrylic acid (GO/PAA) nanocomposite hydrogel synthesized with a simple PAA cross-linking reaction. Both the compressive strength and water absorbing capacity of the GO/PAA nanocomposite hydrogel were enhanced after adding GO [33]. However, these researches have been focused on the development of various binary kinds of composite material; ternary composite materials have been rarely reported; among them, PNIPAM/KGM/GO composite membranes have not been studied.

Therefore, temperature-sensitive composite membranes should be designed to improve mechanical property, water absorbing capacity, and biodegradability. In this study, we prepared novel PNIPAM/KGM/GO temperature-responsive composite membranes by solution blending using ionic cross-linking of calcium ions. This method is facile, and the preparation procedure is easy to control. PNIPAM and KGM by hydrogen bonding formed the network structure of the PNPAM/KGM composite membranes. When GO sheets were introduced into the PNPAM/KGM composite membranes, the chemical cross-linking points from the GO sheets were produced via $\mathrm{Ca}^{2+}$ as a cross-linking agent in the structure of PNIPAM/KGM/GO composite membranes. The schematic of the PNIPAM/KGM/GO ternary composite membranes is exhibited in Scheme 1. The PNIPAM/KGM/GO composite membranes possessed the unique temperature sensitivity of PNIPAM and enzymatic degradation property of KGM, and GO could improve the performance of the composite membranes. The mechanical property, phase transformation behavior, swelling behavior, and enzymatic degradation of the PNIPAM/KGM/GO composite films were studied.

\section{Experimental}

2.1. Materials. N-Isopropylacrylamide (NIPAM) was recrystallized in hexane before use to remove inhibitors and purchased from Shanghai Wujing Chemical Technology Co., Ltd. N,N ${ }^{\prime}$-Methylenebisacrylamide (MBA), potassium persulfate (KPS), and sodium bisulfite (SBS) were obtained from Kelong Chemical Inc. Konjac glucomannan (KGM) was purchased from Sichuan Taro Zi Source Food Co., Ltd. Graphene oxide (GO) was obtained from Aladdin (Shanghai, China). $\beta$-Mannanase was purchased from Jiangsu Ruiyang Biotechnology Co., Ltd. Deionized water was used in all experiments. All chemicals were of analytical grade and were used without further purification. 
2.2. Characterization. The prepared materials were compressed into pellets using $\mathrm{KBr}$ and the pellets were investigated by Fourier-transform infrared spectra (FT-IR, Nicolet5700, Perkin Elmer Instruments Corporation) within the wavenumber range of $500-4000 \mathrm{~cm}^{-1}$. Raman spectroscopy (InVia, Renishaw, $514.5 \mathrm{~nm}$ ) was used to investigate the nature of the chemical functional groups of the composite films. The SEM images were obtained on a field emission scanning electron microscope (FESEM, Ultra 55) at an accelerating voltage of $15 \mathrm{kV}$ after the sputter coating of gold on the specimen surface. The structure of PNIPAM/KGM/GO was determined through X-ray powder diffraction (XRD; X'Pert $\mathrm{PRO}$ ) with $\mathrm{Cu} \mathrm{Ka}$ radiation, $2 \theta=8^{\circ}$ to $28^{\circ}$. The LCST measurements of the wet samples were carried out on a DSC Q2000 differential scanning calorimeter (DSC) under a nitrogen atmosphere, at a heating rate of $10^{\circ} \mathrm{C} \cdot \mathrm{min}^{-1}$ from -40 to $80^{\circ} \mathrm{C}$, and the flow rate of $\mathrm{N}_{2}$ was adjusted at $100 \mathrm{~mL} \cdot \mathrm{min}^{-1}$; the purity of $\mathrm{N}_{2} \geq 99.999 \%$.

2.2.1. Mechanical Properties. The mechanical properties of the composite membranes were measured using the temperature-controlled electronic universal material testing machine (MTS, C45.504, China) at a strain rate of $10 \mathrm{~mm} \cdot \mathrm{min}^{-1}$ at room temperature. The tensile test was carried out on a C45.504E computer-controlled electronic universal testing machine (MTS Industrial Systems Co., Ltd., China) at a rate of $2 \mathrm{~mm} \cdot \mathrm{min}^{-1}$ based on GB/T 1040.3-2006 (China). The samples were cut in a dumbbell shape with the dimension of $110 \times 7 \times 0.2 \mathrm{~mm}$ for tensile test. The average of three specimens per sample was taken as the final value.

2.2.2. Swelling Behavior. The swelling ratios of membranes samples were measured at room temperature using a gravimetric method. The dried membranes were immersed in distilled water until their weight became constant. The membranes were then removed from water and their surfaces were blotted with filter paper before being weighed. For each sample, a minimum of three measurements was taken, and the swelling ratio was calculated with the following equation:

$$
\text { swelling ratio }=\frac{\left(W_{s}-W_{d}\right)}{W_{d}},
$$

where $W_{s}$ is the weight of the swollen membranes and $W_{d}$ is the weight of the dry membranes.

The swelled membranes at room temperature were put into water of $50^{\circ} \mathrm{C}$ to deswell. The deswelling behavior of the membranes was studied by recording the weight of water in the membranes at $50^{\circ} \mathrm{C}$. For each sample, a minimum of three measurements was taken, and water retention was calculated as follows.

$$
\text { Water retention }=\frac{\left(W_{t}-W_{d}\right)}{\left(W_{e}-W_{d}\right)} \text {, }
$$

where $W_{e}$ is the weight of membranes equilibrated at room temperature, $W_{t}$ is the weight of membranes at time $t$, and $W_{d}$ is the weight of dry membranes.
2.2.3. Degradation Behavior. The enzymatic degradation of the composite membranes was carried out in a flask filled with $25 \mathrm{~mL}$ phosphate buffer $\left(\mathrm{pH} 7.40,0.1 \mathrm{~mol} \cdot \mathrm{L}^{-1}\right.$, $37^{\circ} \mathrm{C}$ ) which contained determined content of $\beta$-mannanase $\left(0.2 \mathrm{mg} \cdot \mathrm{mL}^{-1}\right.$ and $\left.0.4 \mathrm{mg} \cdot \mathrm{mL}^{-1}\right)$. The degradation experiments were conducted by immersing the dry membranes $(10 \mathrm{mg})$ mass in buffer solutions and they were placed in a thermostatic shaker $\left(37^{\circ} \mathrm{C}, 50 \mathrm{r} \cdot \mathrm{min}^{-1}\right)$. The degradation of the membranes was expressed by the degradation rate $\left(\mathrm{DR}_{t}\right)$ of the samples at predetermined time intervals. After a predetermined time, the samples were removed from the solution, the enzymatic degradation was stopped, and the samples were washed thoroughly with ethanol and then dried at $30^{\circ} \mathrm{C}$. The degradation ratio of the test samples was calculated by the following expression:

$$
\mathrm{DR}_{t}=\frac{\left(M_{i}-M_{t}\right)}{M_{i}},
$$

where $M_{i}$ is the initial weight of the dry gels and $M_{t}$ is the weight at time $t$.

\subsection{Sample Preparation}

2.3.1. Preparation of PNIPAM/KGM Composite Membranes. PNIPAM hydrogels were prepared using improved free radical polymerization method [3]. Firstly, the initial solution consisting of monomer NIPAM (1.000 g), MBA (0.050 g), and SBS $(0.0139 \mathrm{~g})$ was dissolved in deionized water $(100 \mathrm{~mL})$ with stirring under $\mathrm{N}_{2}$ for $30 \mathrm{~min}$ at $5^{\circ} \mathrm{C}$. Secondly, an aqueous solution of the initiator KPS $(0.0361 \mathrm{~g})$ was added to the solution. The free radical polymerization was carried out in an ice-water bath at $5^{\circ} \mathrm{C}$ for $24 \mathrm{~h}$. The samples were stewed for $4 \mathrm{~h}$, immersed with deionized water for $48 \mathrm{~h}$, freezedried for $24 \mathrm{~h}$, and stored. The detailed steps for preparing the PNIPAM/KGM composite membranes were described as follows. Firstly, KGM (0.600 g) was dissolved in deionized water $(6 \mathrm{~mL})$ and then calcium hydroxide $\left(\mathrm{Ca}(\mathrm{OH})_{2}, 2.5 \mathrm{~mL}\right)$ was added and heated at $90^{\circ} \mathrm{C}$ for $4 \mathrm{~h}$ for deacetylation. KGM formed thermally stable hydrogels when heated with alkali by deacetylation and disruption of the hydrogen bonding of the hydration between the macromolecular chain and water molecule [37]. KGM hydrogels were added to the above PNIPAM hydrogels with mechanical stirring for $4 \mathrm{~h}$ at $5^{\circ} \mathrm{C}$. The obtained products were immersed with deionized water at room temperature for $48 \mathrm{~h}$ and were poured on the PET film by solution-casting method. Finally, the PNIPAM/KGM composite membranes were dried at $30^{\circ} \mathrm{C}$ in a vacuum dryer. Among them, the quality of KGM was set as $0.600 \mathrm{~g}$ after a series of tests.

\subsubsection{Preparation of PNIPAM/KGM/GO Composite Mem-} branes. Firstly, the purified GO $(1.00 \mathrm{mg})$ was dispersed in deionized water $(10 \mathrm{~mL})$ and sonicated for $3 \mathrm{~h}$ to obtain a homogeneous dispersion. After the GO dispersion was added dropwise to the PNIPAM/KGM combined solution, $\mathrm{Ca}(\mathrm{OH})_{2}$ $(2.5 \mathrm{~mL})$ was added to the reaction; the PNIPAM/KGM/GO mixture solution was stirred for another $4 \mathrm{~h}$. The obtained products were immersed with deionized water at room temperature for $48 \mathrm{~h}$. Then the resulting products were poured on 
TABLE 1: The compositions of PNIPAM/KGM/GO membranes.

\begin{tabular}{lccc}
\hline Sample & NIPAM $(\mathrm{g})$ & KGM $(\mathrm{g})$ & $\mathrm{GO}(\mathrm{g})$ \\
\hline PNIPAM & 1.000 & 0 & 0 \\
PNIPAM/KGM & 1.000 & 0.600 & 0 \\
PNIPAM/KGM/GO1 & 1.000 & 0.600 & 0.001 \\
PNIPAM/KGM/GO2 & 1.000 & 0.600 & 0.002 \\
PNIPAM/KGM/GO3 & 1.000 & 0.600 & 0.003 \\
\hline
\end{tabular}

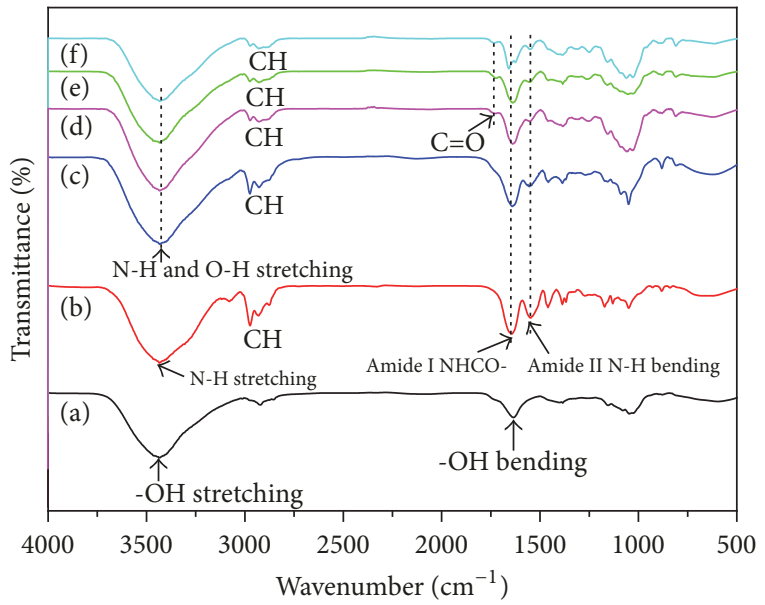

Figure 1: FTIR spectra of KGM (a), PNIPAM (b), PNIPAM/KGM (c), PNIPAM/KGM/GO1 (d), PNIPAM/KGM/GO2 (e), and PNI$\mathrm{PAM} / \mathrm{KGM} / \mathrm{GO} 3$ (f) composite membranes.

the PET film by solution-casting method and were denoted as PNIPAM/KGM/GOn composite membranes. Finally, the composite membranes were dried at $30^{\circ} \mathrm{C}$ in a vacuum dryer. The number $n$ represents the weight percent of GO relative to the NIPAM monomer. The compositions of the PNIPAM/KGM/GO membranes are shown in Table 1.

\section{Results and Discussion}

3.1. Preparation and Characterization of the Composite Membranes. Figure 1 shows the FTIR spectra of the as-prepared products. In Figure 1(a), the pure KGM shows the stretching and bending vibrations of $\mathrm{OH}$ groups occurring at 3442 and $1632 \mathrm{~cm}^{-1}$, respectively [38]. PNIPAM (Figure 1(b)) shows the peak at $3434 \mathrm{~cm}^{-1}$ which was ascribed to $\mathrm{N}-\mathrm{H}$ stretching vibration; the peaks at 2975,2929 , and $2874 \mathrm{~cm}^{-1}$ can be related to the stretching vibrations of $\mathrm{C}-\mathrm{H}$ groups; the characteristics amide I $(\mathrm{C}=\mathrm{O})$ and amide II $(\mathrm{N}-\mathrm{H})$ stretching vibration bands of PNIPAM repeat units were found at 1640 and $1550 \mathrm{~cm}^{-1}[39,40]$. In Figures $1(\mathrm{~d})-1(\mathrm{f})$, the carbonyl band appeared at $1722(\mathrm{C}=\mathrm{O}$ of GO) [19]. These main characteristic peaks in the FT-IR spectra indicated that the PNIPAM/KGM/GO composite membranes have been successfully synthesized.

To further confirm the existence of GO in the composite membranes, the Raman analysis was performed in Figure 2. The peak at about $1355 \mathrm{~cm}^{-1}$ (D band) corresponds to the disorder mode in the aromatic structure of GO, and the peak

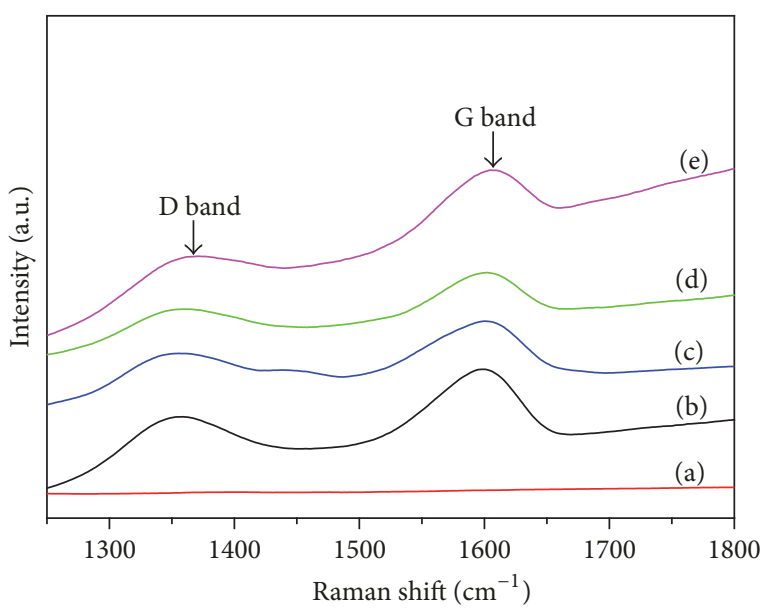

Figure 2: Raman spectra of PNIPAM/KGM (a), GO (b), PNIPAM/ KGM/GO1 (c), PNIPAM/KGM/GO2 (d), and PNIPAM/KGM/GO3 (e) composite membranes.

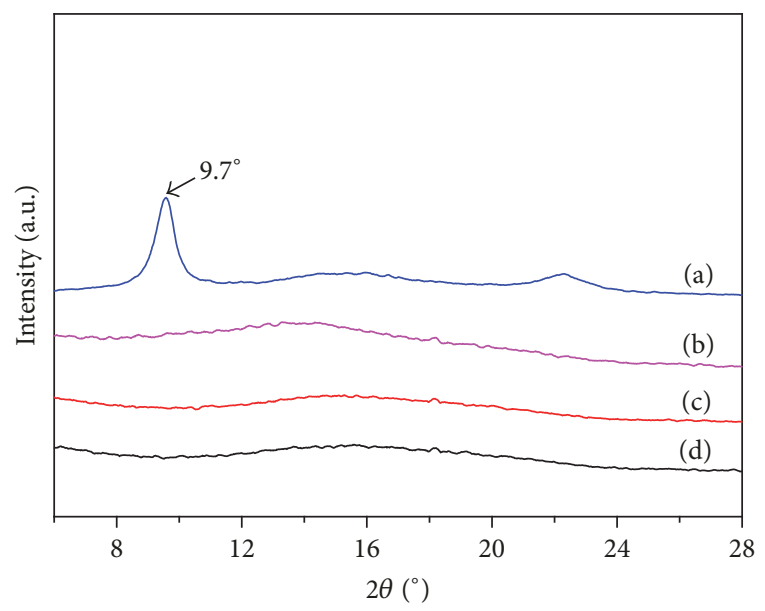

FIGURE 3: XRD patterns of GO (a), PNIPAM/KGM/GO1 (b), PNIPAM/KGM/GO2 (c), and PNIPAM/KGM/GO3 (d) composite membranes.

at about $1600 \mathrm{~cm}^{-1}$ (G band) corresponds to the tangential mode which is due to the plane vibration of the $\mathrm{sp}^{2}$ carbon atoms in GO [41, 42]. The intensity ratio of $\mathrm{D}$ band to $\mathrm{G}$ band $\left(I_{\mathrm{D}} / I_{\mathrm{G}}\right)$ was commonly used to indicate the structure disorder and defect [43]. The $I_{\mathrm{D}} / I_{\mathrm{G}}$ ratios of GO, PNIPAM/KGM/GO1, PNIPAM/KGM/GO2, and PNIPAM/KGM/GO3 were 0.80 , $0.82,0.84$, and 0.85 , respectively (Figures $2(\mathrm{~b})-2(\mathrm{e})$ ). This change suggested that some oxygen functional groups in GO participated in the cross-linking process and were dehydrated, and the $\mathrm{C}=\mathrm{C}$ bonds were partially restored, resulting in the increase in $I_{\mathrm{D}} / I_{\mathrm{G}}[44]$.

Figure 3 shows the XRD patterns of GO (Figure 3(a)), PNIPAM/KGM/GO1 (Figure 3(b)), PNIPAM/KGM/GO2 (Figure 3(c)), and PNIPAM/KGM/GO3 (Figure 3(d)) composite membranes. After cross-linking reaction, GO was incorporated into PNIPAM/KGM; the peaks of the PNIPAM/KGM/GO composite membranes became broader and had no distinct diffraction peak at around $2 \theta=9.7^{\circ}$, 


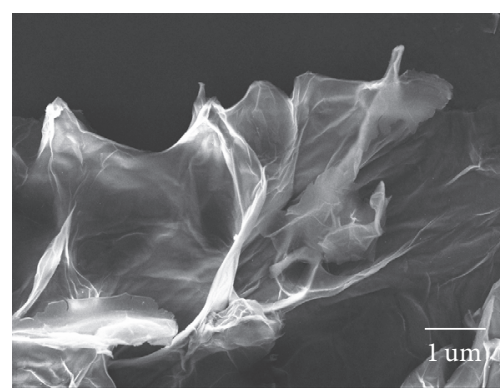

(a)

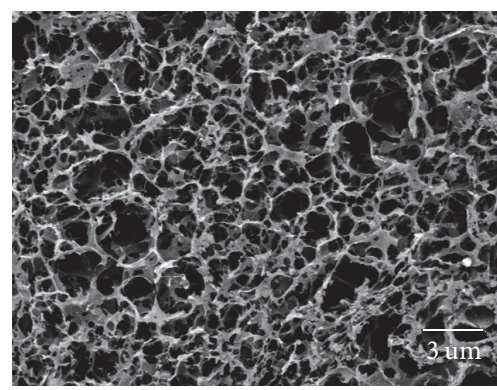

(d)

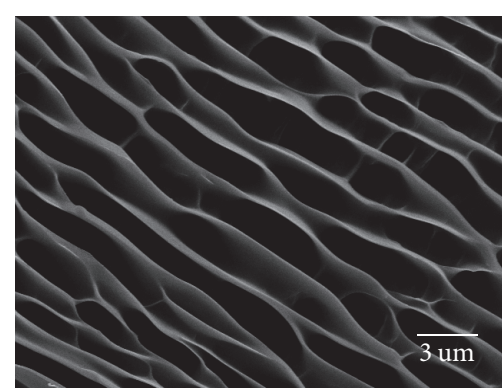

(b)

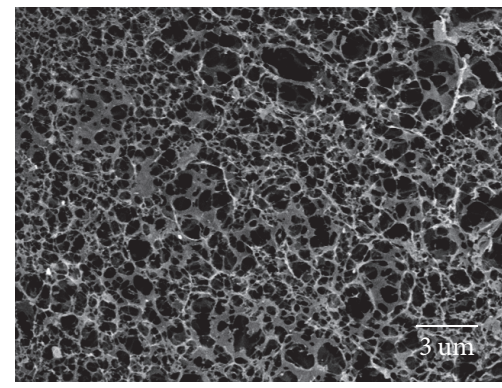

(e)

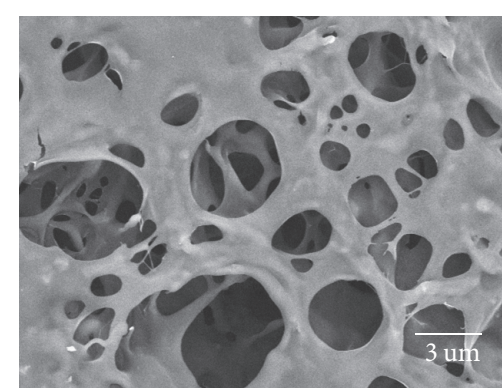

(c)

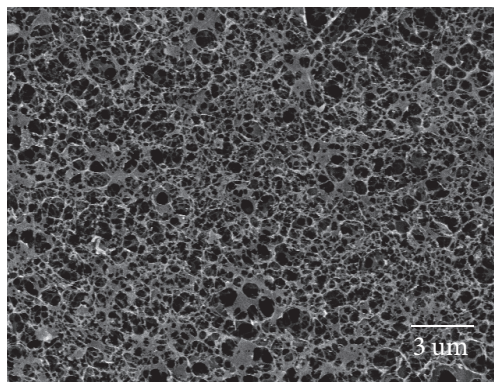

(f)

Figure 4: SEM images of GO (a), PNIPAM (b), PNIPAM/KGM (c), PNIPAM/KGM/GO1 (d), PNIPAM/KGM/GO2 (e), and PNIPAM/ KGM/GO3 (f) composite membranes.

where GO showed a diffraction peak at $2 \theta=9.7^{\circ}$ with $c a$. $1.06 \mathrm{~nm}$ interlayer spacing. The XRD results demonstrated that GO was uniformly dispersed in the polymer matrix without ordered aggregation $[42,45]$.

The morphologies of the freeze-dried composite membranes were observed by SEM. Figure 4 shows the obvious differences in the internal structures of GO, PNIPAM, PNIPAM/KGM, PNIPAM/KGM/GO1, PNIPAM/KGM/GO2, and PNIPAM/KGM/GO3 composite membranes. The pure GO presented a monolayer sheetlike structure, along with smooth surface (Figure 4(a)) [46]. Compared with GO, PNIPAM showed various pores, which resembled a net structure (Figure $4(\mathrm{~b})$ ). The PNIPAM/KGM composite membranes exhibited an irregular porous structure (Figure 4(c)), but the PNIPAM/KGM/GO composite membranes showed a three-dimensional porous structure, and the pore size becomes smaller with increasing the GO content (Figures 4(d)-4(f)). The pore density increase of composite membranes could avoid collapse of the pore structure and enhance water retention of composite membranes.

3.2. Thermoresponsive Behavior. The temperature behavior of the synthesized hydrogels was determined through DSC with the LCST reported as the peak temperature [29]. Figure 5(a) shows that PNIPAM (Figure 5(A)), PNIPAM/ KGM (Figure 5(B)), PNIPAM/KGM/GO1 (Figure 5(C)), PNIPAM/KGM/GO2 (Figure 5(D)), and PNIPAM/KGM/ GO3 (Figure 5(E)) composite membranes exhibited the LCST around $35.6^{\circ} \mathrm{C}, 35.2^{\circ} \mathrm{C}, 34.8^{\circ} \mathrm{C}, 34.6^{\circ} \mathrm{C}$, and $34.5^{\circ} \mathrm{C}$, respectively. In addition, the LCST of the PNIPAM/KGM/GO composite membranes gradually decreased with increasing GO sheet content, but the change was weak. These results indicated that the incorporation of the GO sheets had a minor effect on the LCST of the composite membranes, and the composite membranes still maintained the temperature sensitivity of PNIPAM.

Figure 5(b) shows the digital photos of the sample sizes compared based on the same swatches when the water temperatures rises from 25 to $37^{\circ} \mathrm{C}$. The transparent hydrogels first change from white to brown with increasing GO content. At temperatures below the LCST of the composite membrane, the PNIPAM (B1), PNIPAM/KGM (B2), and PNIPAM/KGM/GO3 (B3) composite membranes showed a swollen state. By contrast, the PNIPAM (B4), PNIPAM/KGM (B5), and PNIPAM/KGM/GO3 (B6) composite membranes were in a shrunken state at temperatures above the LCST, and their sizes became small. At 25 and $37^{\circ} \mathrm{C}$, the size of all samples ranged from $2.0,2.5$, and $2.3 \mathrm{~cm}$ to $1.5,2.0$, and $2.0 \mathrm{~cm}$. This further indicated that the prepared composite membranes were sensitive to temperature, which could be suitable for application in smart skin dressings.

3.3. Mechanical Properties. Composite membranes as wound dressings should have appropriate mechanical properties. Figure 6 shows the strain-stress curves of PNIPAM/KGM, PNIPAM/KGM/GO1, PNIPAM/KGM/GO2, and PNIPAM/ KGM/GO3 composite membranes. Compared with PNIPAM/ KGM composite membranes, the GO addition enhanced the mechanical strength of PNIPAM/KGM/GO composite membranes. On one hand, GO can act as an effective reinforcing filler for enhancing the mechanical performance 


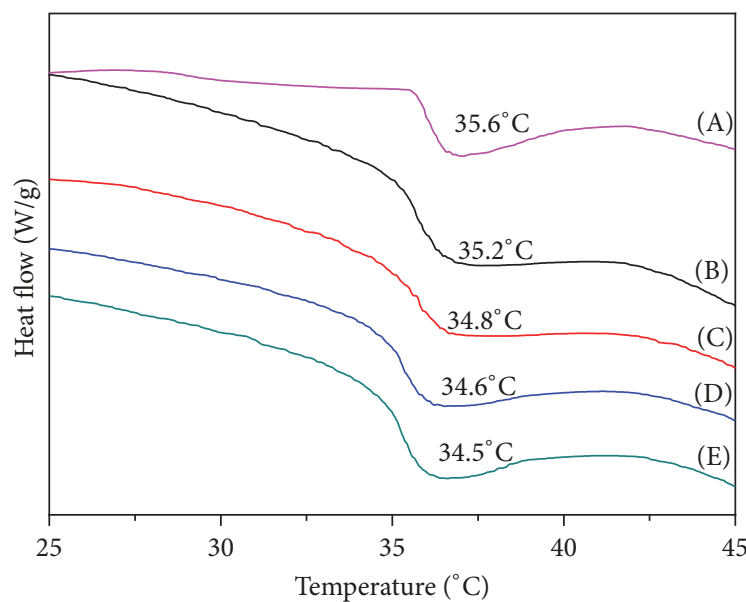

(a)
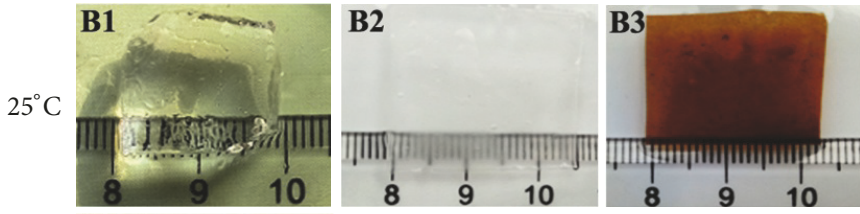

$37^{\circ} \mathrm{C}$

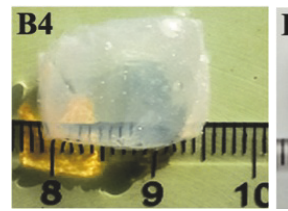

B5

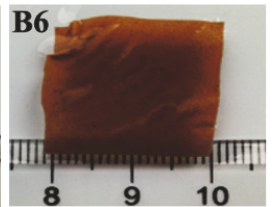

(b)

Figure 5: (a) DSC thermograms of PNIPAM (A), PNIPAM/KGM (B), PNIPAM/KGM/GO1 (C), PNIPAM/KGM/GO2 (D), and PNIPAM/ KGM/GO3 (E) composite membranes. (b) PNIPAM (B1 and B4), PNIPAM/KGM (B2 and B5), and PNIPAM/KGM/GO3 (B3 and B6) composite membranes with the volume conversion at $25^{\circ} \mathrm{C}$ and $37^{\circ} \mathrm{C}$, respectively.

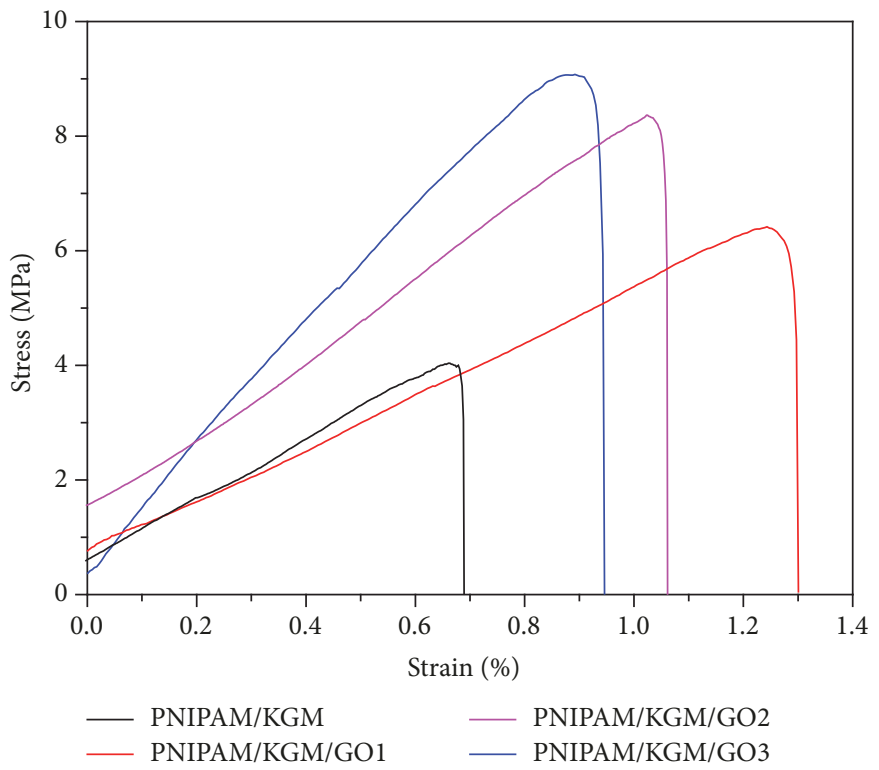

FIGURE 6: Stress-strain curves of PNIPAM/KGM, PNIPAM/KGM/GO1, PNIPAM/KGM/GO2, and PNIPAM/KGM/GO3 composite membranes.

of the PNIPAM/KGM/GO composite membranes [27]. On the other hand, the incorporation of GO improves the mechanical property of the PNIPAM/KGM/GO composite membranes which were fabricated through solution blending of PNIPAM and KGM in the presence of GO in aqueous system followed by calcium ions cross-linking. However, the strain for the PNIPAM/KGM/GO composite membranes showed a decreasing trend with increasing contents of GO, indicating that $\mathrm{GO}$ with a few linkages with a polymer may act as a defect, thereby leading to the brittleness of PNIPAM/KGM/GO [31]. Table 2 shows the values reported for human skin and compares the mechanical properties of human skin with the prepared PNIPAM/KGM/GO composite membranes. The results reveal that the mechanical properties of the composite membranes are in the range of skin bearing. Furthermore, one can tune the mechanical properties of the GO-reinforced PNIPAM/KGM composite membranes depending on the applicability of the material via the GO concentration [47].

3.4. Swelling Behavior. Figure 7(a) shows the water holding capacity of the composite membranes in terms of their swelling ratio. Both pure and composite membranes quickly became swollen at the initial stage and then began to level off with increasing time. The swelling equilibrium could be achieved within $120 \mathrm{~min}$. The swelling ratio of the PNIPAM/KGM composite membranes was increased with increasing KGM content compared with PNIPAM. This 
TABLE 2: Comparison of mechanical properties of PNIPAM/KGM/GO composite membranes to those of human skin.

\begin{tabular}{|c|c|c|c|c|}
\hline Skin location & Tensile strength $(\mathrm{MPa})$ & Young's modulus (MPa) & Elongation at break (\%) & Reference \\
\hline Back & $13.2-30$ & $48.4-118.2$ & $37-71$ & {$[34]$} \\
\hline Abdomen + thorax & $2-15$ & 18.8 & & [35] \\
\hline Forehead and arm & $5.7-12.6$ & $19.5-87.1$ & $27-59$ & {$[36]$} \\
\hline PNIPAM/KGM & 4.85 & 57.88 & 8.41 & \\
\hline PNIPAM/KGM/GO1 & 6.92 & 134.24 & 5.15 & \\
\hline PNIPAM/KGM/GO2 & 8.14 & 278.07 & 3.74 & \\
\hline PNIPAM/KGM/GO3 & 9.86 & 385.29 & 2.56 & \\
\hline
\end{tabular}

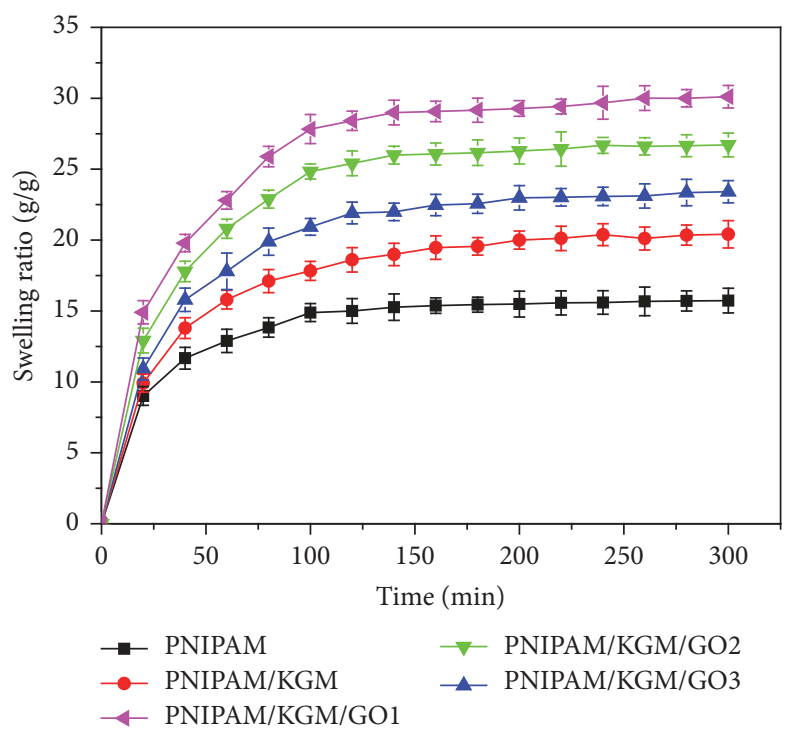

(a)

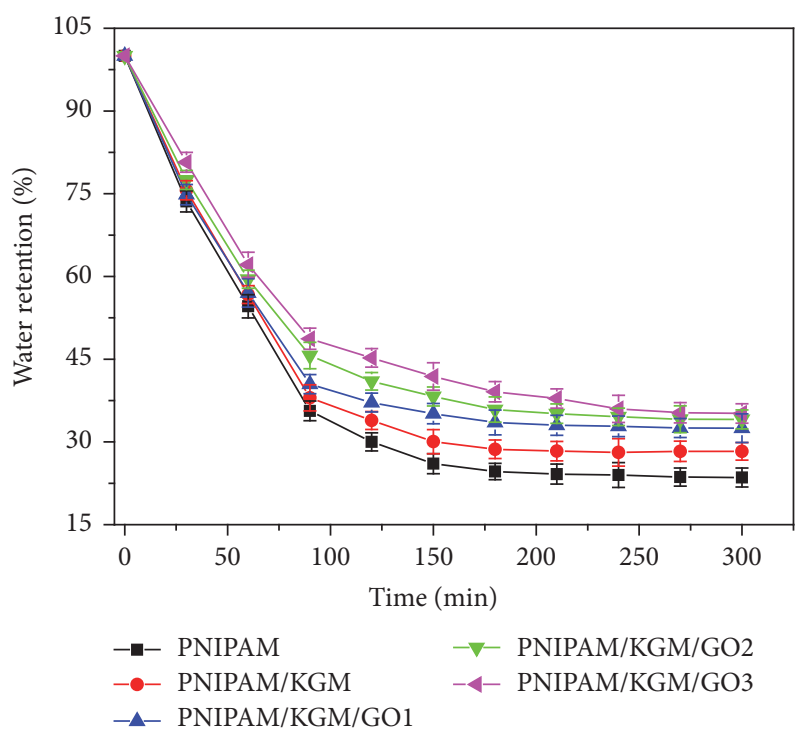

(b)

FIGURE 7: Swelling ratios (a) and water retention (b) of conventional PNIPAM, PNIPAM/KGM, and PNIPAM/KGM/GO composite membranes with different amounts of $\mathrm{GO}$ at $20^{\circ} \mathrm{C}$ and $50^{\circ} \mathrm{C}$, respectively.

phenomenon was mainly attributed to the strong hydrophilic property of the amide group, which caused the strong water absorption of the PNIPAM chain segment and the good water absorption of KGM. The incorporation of GO obviously improved the swelling ratio of the composite membranes compared with the PNIPAM and PNIPAM/KGM composite membranes $[48,49]$. However, the swelling ratio of the PNI$\mathrm{PAM} / \mathrm{KGM} / \mathrm{GO}$ composite membranes was decreased with further increase of GO content, which could be attributed to the relatively compact polymer network structure.

Figure 7(b) shows the water retention of composite membranes at $50^{\circ} \mathrm{C}$. The prepared composite membranes presented similar deswelling behavior to the PNIPAM. By contrast, the water retention of the PNIPAM/KGM/GO composite membranes was higher than that of the PNIPAM and PNI$\mathrm{PAM} / \mathrm{KGM}$ composite membranes. This observation indicated that the PNIPAM/KGM/GO composite membranes attained stable water retentions much slower than the PNI$\mathrm{PAM} / \mathrm{KGM}$ composite membranes upon deswelling under identical conditions. In other words, the PNIPAM/KGM/GO composite membranes displayed much more stable water retention than the conventional PNIPAM/KGM composite membranes.
3.5. Degradation Behavior. The enzymatic hydrolysis experiment was carried out in $\mathrm{pH} 7.40$ buffer solution with $\beta$ mannanase at $37^{\circ} \mathrm{C}$ to estimate the biodegradability of the PNIPAM/KGM/GO composite membranes.

Figure 8 shows the degradation rate of the different membranes under different concentrations of $\beta$-mannanase. The degradation rate of PNIPAM almost remained unchanged in $\mathrm{pH} 7.4$ buffer solution with $\beta$-mannanase at $37^{\circ} \mathrm{C}$, whatever the enzyme concentration is $0.2 \mathrm{mg} \cdot \mathrm{mL}^{-1}$ or 0.4 $\mathrm{mg} \cdot \mathrm{mL}^{-1}$. The results show that PNIPAM could not be degraded in $\mathrm{pH} 7.4$ buffer solution with $\beta$-mannanase at $37^{\circ} \mathrm{C}$. However, KGM, PNIPAM/KGM, PNIPAM/KGM/GO1, PNIPAM/KGM/GO2, and PNIPAM/KGM/GO3 composite membranes could be degraded by $\beta$-mannanase, and when the enzyme concentration increased from 0.2 to $0.4 \mathrm{mg} \cdot \mathrm{mL}^{-1}$, the degradation rate was increased from $58 \%$ to $70 \%$, from $46 \%$ to $60 \%$, from $65 \%$ to $79 \%$, from $62 \%$ to $75 \%$, and from $60 \%$ to $72 \%$ for $24 \mathrm{~h}$, respectively. The results indicated that different concentrations of $\beta$-mannanase displayed a major effect, and the increase in enzyme concentration improved the degradation rate of the composite membranes. Meanwhile, KGM composite can be degraded by the enzymes which can degrade KGM itself; that is, PNIPAM/KGM/GO 


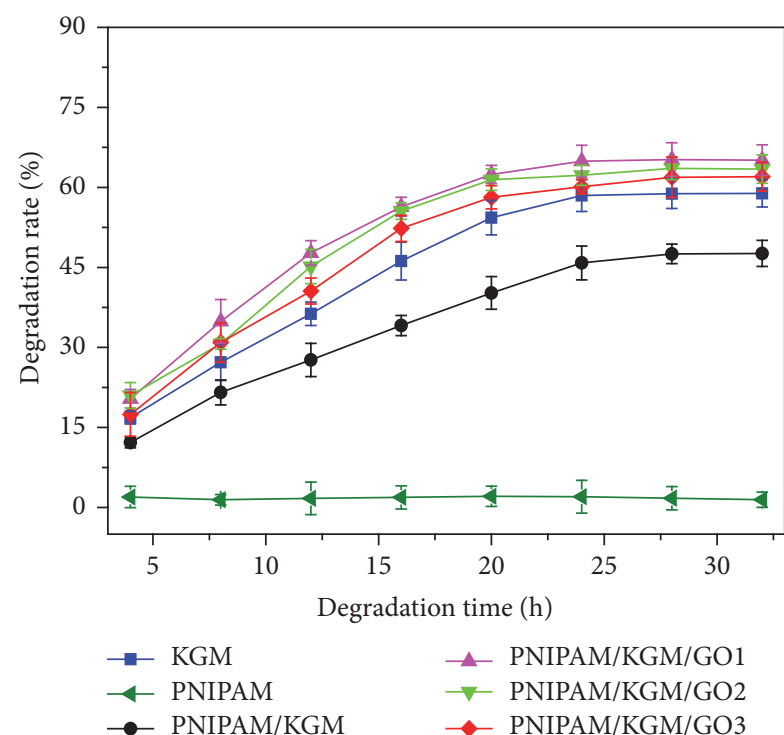

(a)

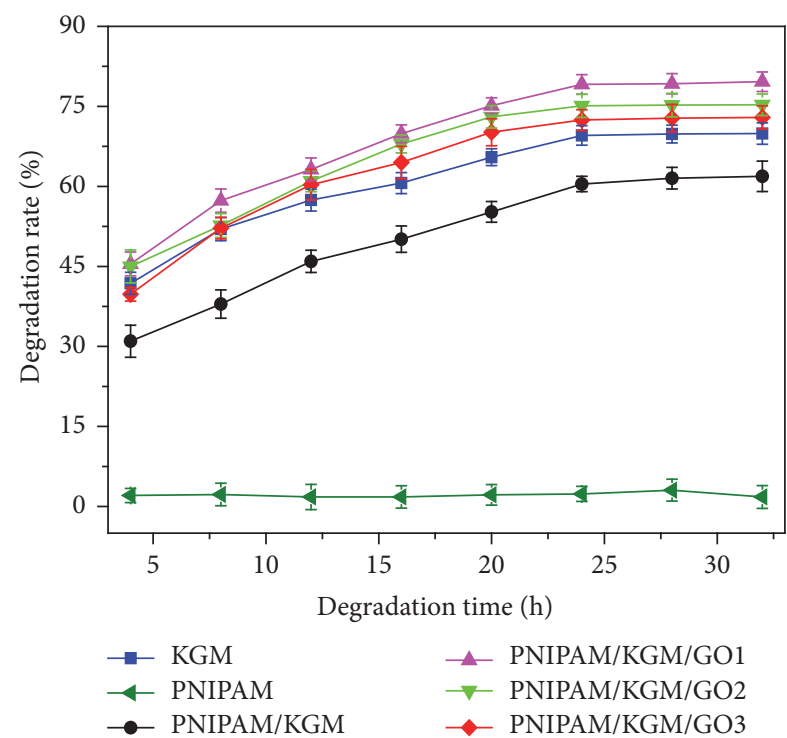

(b)

FIGURE 8: Degradation rate of conventional KGM, PNIPAM, PNIPAM/KGM, and PNIPAM/KGM/GO composite membranes with different amounts of GO in buffer solution of $\mathrm{pH} 7.40$ with 0.2 (a) and $0.4 \mathrm{mg} \cdot \mathrm{mL}^{-1}$ (b) $\beta$-mannanase at $37^{\circ} \mathrm{C}$.

composite membranes retain the biodegradability characters of KGM [50]. The effect of the GO contents on degradation was not investigated. The degradation rate of the PNI$\mathrm{PAM} / \mathrm{KGM} / \mathrm{GO}$ composite membranes was decreased with the increase of the GO content, but the composite membrane showed a higher degradation rate compared with the KGM membrane and PNIPAM/KGM composite membranes. This behavior may be attributed to the $\mathrm{Ca}^{2+}$ cross-linking of GO with PNIPAM and KGM macromolecules, which overcame the disintegration of the gels and the interactions between the polysaccharides and GO strengthened as the GO content increased.

\section{Conclusion}

In summary, a novel temperature-responsive composite membrane was successfully prepared, which was based on GO incorporated in PNIPAM/KGM by solution blending using ionic cross-linking of calcium ions. The mechanical property, swelling behavior, and enzymatic degradation of the PNIPAM/KGM/GO composite membranes were studied. The presence of GO improved the mechanical property, swelling behavior, and enzymatic degradation of PNIPAM/KGM. In particular, with increasing the GO content, the PNIPAM/KGM/GO composite membranes showed enhanced tensile strength from $4.85 \mathrm{MPa}$ to $9.86 \mathrm{MPa}$ (2.03-fold increase) compared with the conventional PNI$\mathrm{PAM} / \mathrm{KGM}$ composite membranes. Furthermore, regarding the mechanical properties of PNIPAM/KGM/GO composite membranes compared with human skin, the results reveal that the mechanical properties of PNIPAM/KGM/GO composite membranes can be adjusted via changing GO concentration. When the enzyme concentration increased from $0.2 \mathrm{mg} \cdot \mathrm{mL}^{-1}$ to $0.4 \mathrm{mg} \cdot \mathrm{mL}^{-1}$, the degradation rate of the
PNIPAM/KGM/GO1 composite membranes was increased from $65 \%$ to $79 \%$ in $24 \mathrm{~h}$. The above-mentioned advantages demonstrated the suitability of the PNIPAM/KGM/GO composite membranes for many applications in the biomedical field.

\section{Conflicts of Interest}

The authors declare that there are no conflicts of interest regarding the publication of this paper.

\section{Acknowledgments}

This work was financially supported by the National Natural Science Foundation of China (nos. 21201142 and 11502158) and Longshan Academic Talent Research Supporting Program of SWUST (Grant no. 17LZX405).

\section{References}

[1] K.-S. Chen, Y.-A. Ku, C.-H. Lee, H.-R. Lin, F.-H. Lin, and T.$\mathrm{M}$. Chen, "Immobilization of chitosan gel with cross-linking reagent on PNIPAAm gel/PP nonwoven composites surface," Materials Science and Engineering C: Materials for Biological Applications, vol. 25, no. 4, pp. 472-478, 2005.

[2] E. Shams, H. Yeganeh, H. Naderi-Manesh, R. Gharibi, and Z. Mohammad Hassan, "Polyurethane/siloxane membranes containing graphene oxide nanoplatelets as antimicrobial wound dressings: in vitro and in vivo evaluations," Journal of Materials Science: Materials in Medicine, vol. 28, no. 5, article no. 75, 2017.

[3] Y. Li, L. Zhang, Y. Zuo, W. H. Yang, J. Shen, and Y. Li, "Poly(N-isopropyl acrylamide)/chitosan composite membrane with smart thermoresponsive performance," Materials Research Innovations, vol. 14, no. 3, pp. 252-257, 2013. 
[4] M. Sun, A. Zhu, Q. Zhang, M. Ye, and Q. Liu, "Smart shape-controlled synthesis of poly(N-isopropylacrylamide)/ chitosan $/ \mathrm{Fe}_{3} \mathrm{O}_{4}$ microgels," European Polymer Journal, vol. 66, pp. 569-576, 2015.

[5] H. Zhang, Q. Niu, N. Wang, J. Nie, and G. Ma, "Thermosensitive drug controlled release PLA core/PNIPAM shell fibers fabricated using a combination of electrospinning and UV photo-polymerization," European Polymer Journal, vol. 71, pp. 440-450, 2015.

[6] G. Liao, J. Chen, W. Zeng, C. Yu, C. Yi, and Z. Xu, "Facile Preparation of Uniform Nanocomposite Spheres with Loading Silver Nanoparticles on Polystyrene-methyl Acrylic Acid Spheres for Catalytic Reduction of 4-Nitrophenol," The Journal of Physical Chemistry C, vol. 120, no. 45, pp. 25935-25944, 2016.

[7] J. Qi, W. Lv, G. Zhang, F. Zhang, and X. Fan, "Poly(Nisopropylacrylamide) on two-dimensional graphene oxide surfaces," Polymer Chemistry, vol. 3, no. 3, pp. 621-624, 2012.

[8] W. Zhang, P. Jiang, J. Chen, C. Zhu, Z. Mao, and C. Gao, "Application of melatonin-loaded poly(N-isopropylacrylamide) hydrogel particles to reduce the toxicity of airborne pollutes to RAW264.7 cells," Journal of Colloid and Interface Science, vol. 490, pp. 181-189, 2017.

[9] Y. Zhou, J. Cao, J. Zhao, Y. Xie, J. Fei, and Y. Cai, “Temperatureresponsive amperometric $\mathrm{H} 2 \mathrm{O} 2$ biosensor using a composite film consisting of poly( $\mathrm{N}$-isopropylacrylamide)-b-poly (2acrylamidoethyl benzoate), graphene oxide and hemoglobin," Microchimica Acta, vol. 183, no. 9, pp. 2501-2508, 2016.

[10] G. Wang, R. Xie, X.-J. Ju, and L.-Y. Chu, "Thermo-Responsive Polyethersulfone Composite Membranes Blended with Poly(Nisopropylacrylamide) Nanogels," Chemical Engineering \& Technology, vol. 35, no. 11, pp. 2015-2022, 2012.

[11] Z. Gong, S. Li, W. Han, J. Wang, J. Ma, and X. Zhang, "Recyclable graphene oxide grafted with poly(N-isopropylacrylamide) and its enhanced selective adsorption for phenols," Applied Surface Science, vol. 362, pp. 459-468, 2016.

[12] X. Chen, C. Shi, Z. Wang et al., "Structure and performance of poly(vinylidene fluoride) membrane with temperaturesensitive poly(N-isopropylacrylamide) homopolymers in membrane pores," Polymer Composites, vol. 34, no. 4, pp. 457-467, 2013.

[13] Y. Zhu, C. H. Ni, D. Shao, and X. Jiang, "The preparation of composites of poly(N-isopropylacrylamide) with silica and its application in HPLC for separating naphthalene derivatives," Polymer Composites, vol. 29, no. 4, pp. 415-420, 2008.

[14] R. Jankaew, N. Rodkate, S. Lamlertthon et al., "“Smart" carboxymethylchitosan hydrogels crosslinked with poly $(\mathrm{N}$ isopropylacrylamide) and poly(acrylic acid) for controlled drug release," Polymer Testing, vol. 42, pp. 26-36, 2015.

[15] Z. Abdali, H. Yeganeh, A. Solouk, R. Gharibi, and M. Sorayya, "Thermoresponsive antimicrobial wound dressings via simultaneous thiol-ene polymerization and in situ generation of silver nanoparticles," RSC Advances, vol. 5, no. 81, pp. 66024-66036, 2015.

[16] H.-P. Cong, J.-H. Qiu, and S.-H. Yu, “Thermoresponsive poly(N-isopropylacrylamide)/Graphene/Au nanocomposite hydrogel for water treatment by a laser-assisted approach," Small, vol. 11, no. 9-10, pp. 1165-1170, 2015.

[17] X. Ma, Y. Li, W. Wang, Q. Ji, and Y. Xia, “Temperature-sensitive poly(N-isopropylacrylamide)/graphene oxide nanocomposite hydrogels by in situ polymerization with improved swelling capability and mechanical behavior," European Polymer Journal, vol. 49, no. 2, pp. 389-396, 2013.
[18] W. Zhang, Y. Ding, Q. Feng et al., "Synthesis and characterization of poly( $\mathrm{N}$-isopropylacrylamide)/graphene oxide nanocomposite hydrogels by using glow discharge electrolysis plasma," Soft Materials, vol. 15, no. 1, pp. 73-81, 2016.

[19] J. Wang, C. Liu, Y. Shuai, X. Cui, and L. Nie, "Controlled release of anticancer drug using graphene oxide as a drug-binding effector in konjac glucomannan/sodium alginate hydrogels," Colloids and Surfaces B: Biointerfaces, vol. 113, pp. 223-229, 2014.

[20] J. Chen, W. Zhang, and X. Li, "Preparation and characterization of konjac glucomannan-acrylic acid-diatomite composites," Polymer Composites, vol. 37, no. 12, pp. 3384-3390, 2016.

[21] L. Gan, S. Shang, E. Hu, C. W. M. Yuen, and S.-X. Jiang, "Konjac glucomannan/graphene oxide hydrogel with enhanced dyes adsorption capability for methyl blue and methyl orange," Applied Surface Science, vol. 357, pp. 866-872, 2015.

[22] X. Chen, S. Wang, M. Lu et al., "Formation and characterization of light-responsive TEMPO-oxidized konjac glucomannan microspheres," Biomacromolecules, vol. 15, no. 6, pp. 2166-2171, 2014.

[23] L. Yang, D. Shen, and S. Gao, "Reinforcing and toughening of polyurethane by chemically modified Konjac glucomannan nanocrystal," Polymer Composites, vol. 38, no. 7, pp. 1447-1453, 2015.

[24] C. Niu, W. Wu, Z. Wang, S. Li, and J. Wang, "Adsorption of heavy metal ions from aqueous solution by crosslinked carboxymethyl konjac glucomannan," Journal of Hazardous Materials, vol. 141, no. 1, pp. 209-214, 2007.

[25] J. He, X. Zhu, Z. Qi et al., "Killing dental pathogens using antibacterial graphene oxide," ACS Applied Materials \& Interfaces, vol. 7, no. 9, pp. 5605-5611, 2015.

[26] X. Mi, G. Huang, W. Xie, W. Wang, Y. Liu, and J. Gao, "Preparation of graphene oxide aerogel and its adsorption for Cu 2+ ions," Carbon, vol. 50, no. 13, pp. 4856-4864, 2012.

[27] J. Fan, Z. Shi, M. Lian, H. Li, and J. Yin, "Mechanically strong graphene oxide/sodium alginate/polyacrylamide nanocomposite hydrogel with improved dye adsorption capacity," Journal of Materials Chemistry A, vol. 1, no. 25, pp. 7433-7443, 2013.

[28] S. Hashmi, A. GhavamiNejad, F. J. Stadler, and D. Wu, "Oscillations in modulus in solutions of graphene oxide and reduced graphene oxide with grafted poly-N-isopropylamide," Soft Matter, vol. 11, no. 7, pp. 1315-1325, 2015.

[29] Z. Li, J. Shen, H. Ma et al., "Preparation and characterization of $\mathrm{pH}$ - and temperature-responsive hydrogels with surfacefunctionalized graphene oxide as the crosslinker," Soft Matter, vol. 8, no. 11, pp. 3139-3145, 2012.

[30] C.-H. Zhu, Y. Lu, J. Peng, J.-F. Chen, and S.-H. Yu, "Photothermally sensitive poly(N-isopropylacrylamide)/graphene oxide nanocomposite hydrogels as remote light-controlled liquid microvalves," Advanced Functional Materials, vol. 22, no. 19, pp. 4017-4022, 2012.

[31] J. J. Park, E. J. Yu, W.-K. Lee, and C.-S. Ha, "Mechanical properties and degradation studies of poly(D,L-lactide-coglycolide) 50:50/graphene oxide nanocomposite films," Polymers for Advanced Technologies, vol. 25, no. 1, pp. 48-54, 2014.

[32] W.-K. Zhu, H.-P. Cong, H.-B. Yao et al., "Bioinspired, Ultrastrong, Highly Biocompatible, and Bioactive Natural Polymer/Graphene Oxide Nanocomposite Films," Small, vol. 11, no. 34, pp. 4298-4302, 2015.

[33] Z. Tai, J. Yang, Y. Qi, X. Yan, and Q. Xue, "Synthesis of a graphene oxide-polyacrylic acid nanocomposite hydrogel and its swelling and electroresponsive properties," RSC Advances, vol. 3, no. 31, pp. 12751-12757, 2013. 
[34] A. Ní Annaidh, K. Bruyère, M. Destrade, M. D. Gilchrist, and M. Otténio, "Characterization of the anisotropic mechanical properties of excised human skin," Journal of the Mechanical Behavior of Biomedical Materials, vol. 5, no. 1, pp. 139-148, 2012.

[35] F. H. Silver, J. W. Freeman, and D. Devore, "Viscoelastic properties of human skin and processed dermis," Skin Research and Technology, vol. 7, no. 1, pp. 18-23, 2001.

[36] C. Jacquemoud, K. Bruyere-Garnier, and M. Coret, "Methodology to determine failure characteristics of planar soft tissues using a dynamic tensile test," Journal of Biomechanics, vol. 40, no. 2, pp. 468-475, 2007.

[37] X. Luo, P. He, and X. Lin, "The mechanism of sodium hydroxide solution promoting the gelation of Konjac glucomannan (KGM)," Food Hydrocolloids, vol. 30, no. 1, pp. 92-99, 2013.

[38] N. N. Marques, B. V. Lima, V. R. Silveira, B. L. B. Lima, A. M. S. Maia, and R. C. Balaban, "PNIPAM-based graft copolymers prepared using potassium persulfate as free-radical initiator: synthesis reproducibility," Colloid and Polymer Science, vol. 294, no. 6, pp. 981-991, 2016.

[39] H. Xu, X.-D. Yuan, B.-D. Shen et al., "Development of poly(Nisopropylacrylamide)/alginate copolymer hydrogel-grafted fabrics embedding of berberine nanosuspension for the infected wound treatment," Journal of Biomaterials Applications, vol. 28, no. 9, pp. 1376-1385, 2014.

[40] J. Fan, K. Wang, M. Liu, and Z. He, "In vitro evaluations of konjac glucomannan and xanthan gum mixture as the sustained release material of matrix tablet," Carbohydrate Polymers, vol. 73, no. 2, pp. 241-247, 2008.

[41] J. Wang, Z. Ouyang, Z. Ren et al., "Self-assembled peptide nanofibers on graphene oxide as a novel nanohybrid for biomimetic mineralization of hydroxyapatite," Carbon, vol. 89, pp. 20-30, 2015.

[42] S. Sun and P. Wu, "A one-step strategy for thermal- and $\mathrm{pH}-$ responsive graphene oxide interpenetrating polymer hydrogel networks," Journal of Materials Chemistry, vol. 21, no. 12, pp. 4095-4097, 2011.

[43] L. Ji, Y. Wu, L. Ma, and X. Yang, "Noncovalent functionalization of graphene with pyrene-terminated liquid crystalline polymer," Composites Part A: Applied Science and Manufacturing, vol. 72, pp. 32-39, 2015.

[44] T.-X. Jin, C. Liu, M. Zhou, S.-G. Chai, F. Chen, and Q. Fu, "Crystallization, mechanical performance and hydrolytic degradation of poly(butylene succinate)/graphene oxide nanocomposites obtained via in situ polymerization," Composites Part A: Applied Science and Manufacturing, vol. 68, pp. 193-201, 2015.

[45] H. Zhang, D. Zhai, and Y. He, "Graphene oxide/polyacrylamide/carboxymethyl cellulose sodium nanocomposite hydrogel with enhanced mechanical strength: Preparation, characterization and the swelling behavior," RSC Advances, vol. 4, no. 84, pp. 44600-44609, 2014.

[46] N. Pan, Y. Liu, X. Fan, Z. Jiang, X. Ren, and J. Liang, "Preparation and characterization of antibacterial graphene oxide functionalized with polymeric N-halamine," Journal of Materials Science, vol. 52, no. 4, pp. 1996-2006, 2016.

[47] A. Azarniya, N. Eslahi, N. Mahmoudi, and A. Simchi, "Effect of graphene oxide nanosheets on the physico-mechanical properties of chitosan/bacterial cellulose nanofibrous composites," Composites Part A: Applied Science and Manufacturing, vol. 85, pp. 113-122, 2016.

[48] L. Peng, Y. Liu, J. Gong, K. Zhang, and J. Ma, “Continuous fabrication of multi-stimuli responsive graphene oxide composite hydrogel fibres by microfluidics," RSC Advances, vol. 7, no. 31, pp. 19243-19249, 2017.

[49] X. Wang, L.-L. Lu, Z.-L. Yu, X.-W. Xu, Y.-R. Zheng, and S.-H. Yu, "Scalable template synthesis of resorcinolformaldehyde/graphene oxide composite aerogels with tunable densities and mechanical properties," Angewandte Chemie International Edition, vol. 54, no. 8, pp. 2397-2401, 2015.

[50] L.-G. Chen, Z.-L. Liu, and R.-X. Zhuo, "Synthesis and properties of degradable hydrogels of konjac glucomannan grafted acrylic acid for colon-specific drug delivery," Polymer Journal, vol. 46, no. 16, pp. 6274-6281, 2005. 


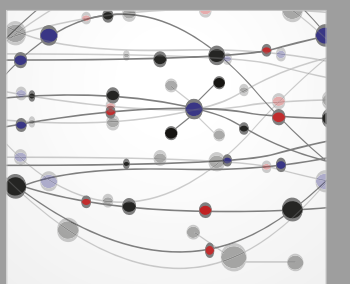

The Scientific World Journal
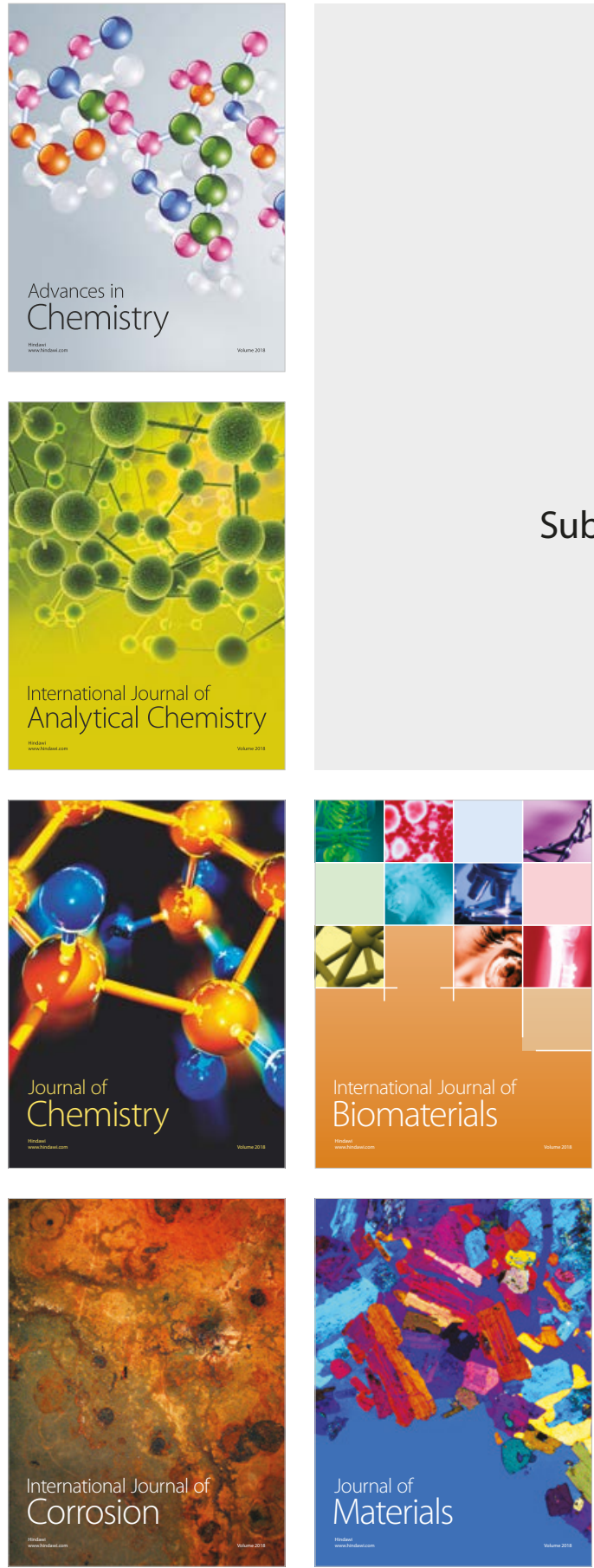

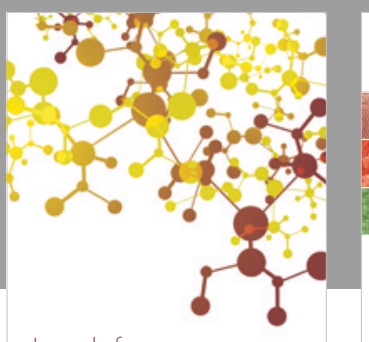

Journal of

Applied Chemistry
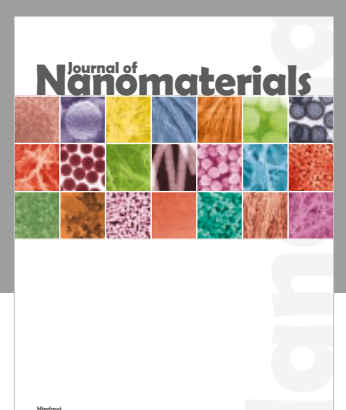

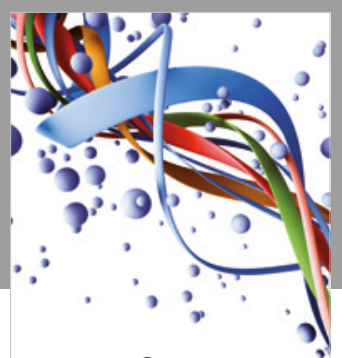

Scientifica

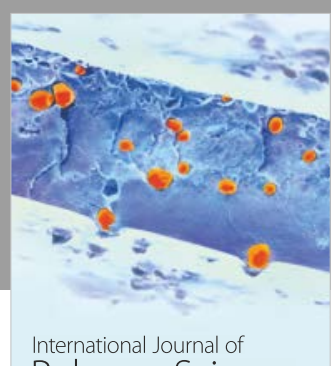

Polymer Science

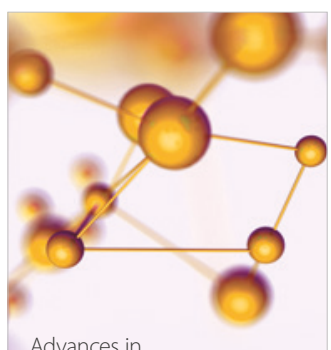

Physical Chemistry
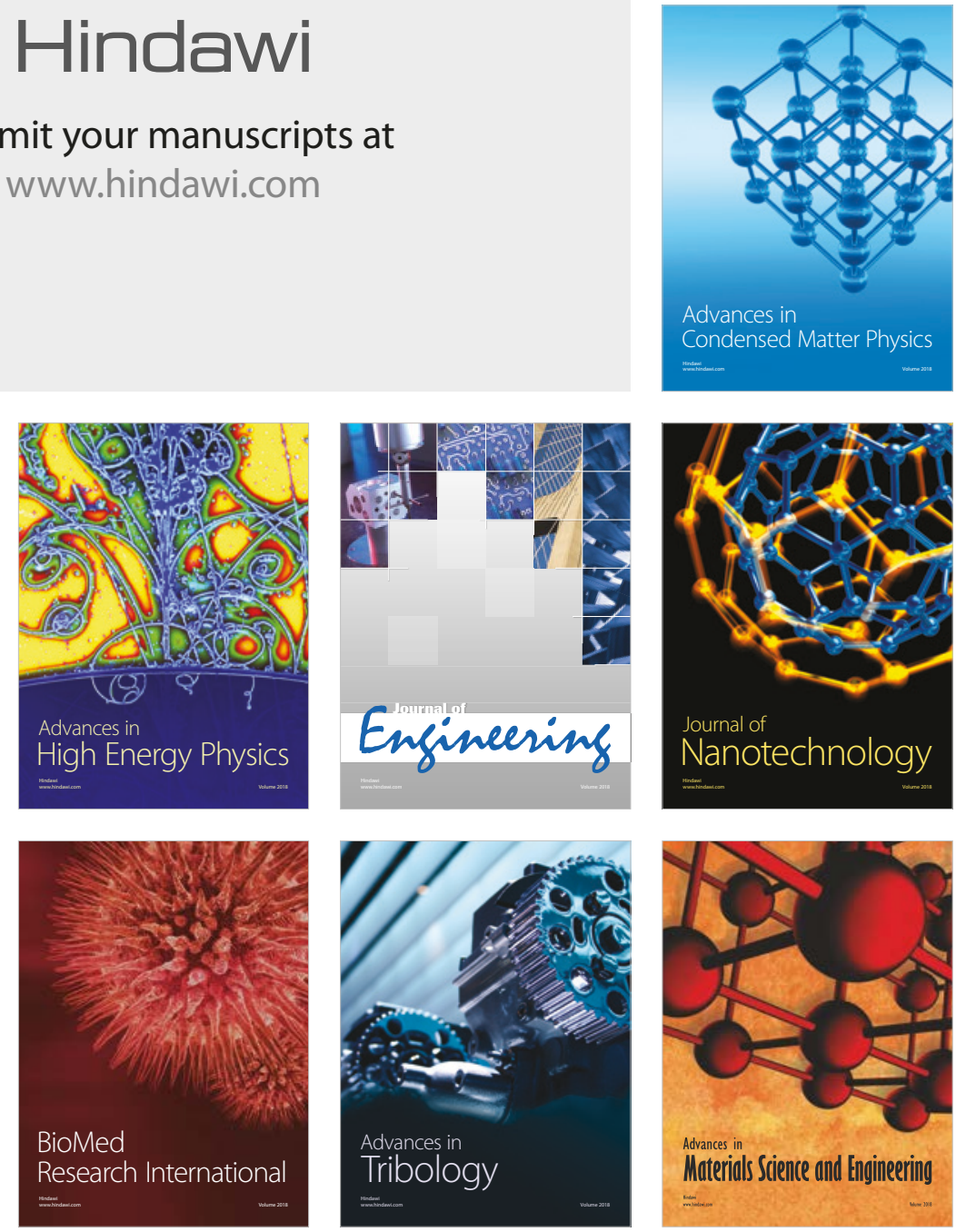